OEM

\title{
Risks for the development of outcomes related to occupational allergies: an application of the asthma-specific job exposure matrix compared with self-reports and investigator scores on job-training-related exposure
}

E Suarthana, D Heederik, H Ghezzo, J-L Malo, S M Kennedy and D Gautrin

Occup. Environ. Med. 2009;66;256-263; originally published online 18 Nov 2008; doi:10.1136/oem.2008.041962

Updated information and services can be found at:

http://oem.bmj.com/cgi/content/full/66/4/256

\section{These include:}

References This article cites 27 articles, 13 of which can be accessed free at: http://oem.bmj.com/cgi/content/full/66/4/256\#BIBL

Rapid responses You can respond to this article at:

http://oem.bmj.com/cgi/eletter-submit/66/4/256

Email alerting Receive free email alerts when new articles cite this article - sign up in the box at service the top right corner of the article

Notes

To order reprints of this article go to:

http://journals.bmj.com/cgi/reprintform

To subscribe to Occupational and Environmental Medicine go to:

http://journals.bmj.com/subscriptions/ 


\title{
Risks for the development of outcomes related to occupational allergies: an application of the asthma- specific job exposure matrix compared with self- reports and investigator scores on job-training- related exposure
}

\author{
E Suarthana, ${ }^{1,2,3}$ D Heederik, ${ }^{2}$ H Ghezzo, ${ }^{1}$ J-L Malo, ${ }^{1}$ S M Kennedy, ${ }^{4}$ D Gautrin ${ }^{1}$
}

\begin{abstract}
${ }^{1}$ Department of Chest Medicine, Hopital du Sacre-Coeur de Montreal, Montreal, Canada; ${ }^{2}$ IRAS (Institute for Risk Assessment Sciences), Division for Environmental Epidemiology, Utrecht University, Utrecht, The Netherlands; ${ }^{3}$ Community Medicine Department, University of Indonesia, Jakarta Pusat, Indonesia; ${ }^{4}$ School of Environmental Health, University of British Columbia, Vancouver, Canada
\end{abstract}

Correspondence to:

Denyse Gautrin, Department of Chest Medicine, Hôpital du

Sacré-Coeur de Montreal, 5400 West Gouin Blvd, Montreal H4J 1C5, Canada; d.gautrin@ umontreal.ca

Accepted 17 October 2008 Published Online First 18 November 2008

\begin{abstract}
Background and aim: Risks for development of occupational sensitisation, bronchial hyper-responsiveness, rhinoconjunctival and chest symptoms at work associated with continued exposure to high molecular weight (HMW) allergens were estimated with three exposure assessment methods.
\end{abstract}

Methods: A Cox regression analysis with adjustment for atopy and smoking habit was carried out in 408 apprentices in animal health technology, pastry making, and dental hygiene technology with an 8-year follow-up after training. The risk of continued exposure after training, estimated by the asthma-specific job exposure matrix (JEM), was compared with self-reports and investigator scores on job-training-related exposure. Associations between outcomes and work duration in job(s) related to training were also evaluated.

Results: Exposure to animal-derived HMW allergens, subsequent to the apprenticeship period, as estimated by the JEM, was associated with a significantly increased risk for occupational sensitisation (hazard ratio (HR) 6.4; $95 \% \mathrm{Cl} 2.3$ to 18.2 ) and rhinoconjunctival symptoms at work (HR 2.6; 95\% Cl 1.1 to 6.2). Exposure to low molecular weight (LMW) agents significantly increased the risk of developing bronchial hyper-responsiveness (HR 2.3; $95 \% \mathrm{Cl} 1.1$ to 5.4). Exposure verification appeared to be important to optimise the sensitivity and the specificity, as well as HRs produced by the JEM. Selfreports and investigator scores also indicated that further exposure to HMW allergens increased the risk of developing occupational allergies. The agreement between self-reports, investigator scores, and the JEM were moderate to good. There was no significant association between respiratory outcomes and work duration in jobs related to training.

Conclusion: The asthma-specific JEM could estimate the risk of various outcomes of occupational allergies associated with exposure to HMW and LMW allergens, but it is relatively labour intensive. Exposure verification is an important integrated step in the JEM that optimised the performance of the matrix.

Published studies establish that exposure is an important predictor of the development of occupational allergies. ${ }^{1}$ Heederik and colleagues demonstrated that the clearest dose-response relationship was observed between exposure intensity and work-related symptoms and sensitisation. ${ }^{23}$ However, when quantitative measurements are lacking, job-specific questionnaires can serve as a good surrogate of exposure level. ${ }^{4}$ Epidemiological studies also suggest that job exposure matrices (JEMs) are useful in assessing exposure at the workplace. The use of a JEM has some advantages over self-reported exposure because exposure classification is performed blinded to health outcome and thus, it is less susceptible to a recall bias. ${ }^{5-8}$ Several generic JEMs exist and assign exposure to a large number of agents based on job titles and industry classifications. A specific JEM was developed by Kennedy and colleagues ${ }^{6}$ and was used to estimate the risk of occupational asthma ${ }^{9}$ and rhinitis ${ }^{10}$ associated with occupational allergens in a questionnaire-based surveillance in the general population. However, its application for estimating the risk of occupational sensitisation and bronchial hyper-responsiveness (BHR) has not been evaluated.

A previous cohort study estimated the incidence of sensitisation to laboratory animal, flour, and latex allergens (per person-year (PY)) at 8.9 per 100 PY, 4.2 per $100 \mathrm{PY}$, and 2.5 per $100 \mathrm{PY}$, for Canadian apprentices in animal health technology, pastry making, and dental hygiene, respectively. ${ }^{11}$ An 8-year follow-up after training was performed to evaluate the long-term effects of occupational exposure to these high molecular weight (HMW) agents on changes in immunological status, symptoms, and bronchial reactivity. ${ }^{12}$ The incidence of sensitisation, rhinoconjunctival and chest symptoms, and BHR at follow-up was higher among subjects who had a job related to training. In contrast, subjects in a job not related to training showed a very high proportion of remission of features that were acquired during apprenticeship. ${ }^{12}$

This study aimed to evaluate the application of the asthma-specific JEM in estimating the risk of occupational sensitisation, BHR, rhinoconjunctival and chest symptoms at work associated with continued exposure to HMW allergens after training in animal health technology, pastry making, and dental hygiene technology. The performance of the JEM was compared with self-reported and investigator scoring on the prolongation of exposure to the relevant HMW allergens beyond the training period. The associations between outcomes and exposure to specific agents as well as duration of exposure were also evaluated. 


\section{METHODS AND MATERIALS}

\section{Study design and population}

A prospective cohort study on the natural history of specific immunological sensitisation and probable occupational asthma was conducted in 769 apprentices during their training in animal health technology, pastry making and dental hygiene (1993-1998). ${ }^{11}{ }^{13}$ A long-term follow-up of 629 eligible subjects from the original cohort was initiated in 2002 to determine the environmental and host determinants for incidence, persistence and improvement of specific immunological sensitisation, workrelated symptoms, bronchial responsiveness and probable occupational asthma. ${ }^{12}$ Testing included completion of questionnaires on symptoms and work history, and skin-prick tests (SPTs) to specific allergens and bronchial challenges. Among the 408 subjects who took part in the follow-up, complete questionnaire data were available for 384; SPT results were available for 368; and BHR data for 281.

To estimate the incidence of outcomes at follow-up, only participants who had no outcome(s) at the end of their apprenticeship were included, leaving a different sample size for different outcomes (fig 1). For occupational sensitisation and BHR, follow-up time was defined as the time between the end of training and the end of follow-up. For rhinoconjunctival and chest symptoms at work, follow-up time was defined as the time between the end of training and the onset of symptoms during follow-up. The number of observations can differ from other published analyses because participants who lacked data on atopy at the end of training were excluded from the analysis, leaving a total of 375 participants. Of these, 83 (22.1\%) had one job, 173 (46.1\%) had two jobs, 78 (20.8\%) had three jobs, 34 (9.1) had four jobs, and seven (1.9\%) had five jobs during follow-up.

The questionnaire was derived from the standardised respiratory questionnaire of the International Union against Tuberculosis and Lung Disease (IUATLD) and was administered by a trained nurse. ${ }^{14}$ Relevant questions on work-related symptoms and work history since the end of the apprenticeship were also administered. Ever smokers were defined as those who have smoked at least 20 packs of cigarettes or $12 \mathrm{oz}$ of tobacco in a lifetime, or one cigarette a day for 1 year from entry in training until follow-up.

Skin tests to work-specific allergens, that is, rat urinary proteins (Pharmacia, Allergon AB, Angelholm, Sweden), mouse dander, rabbit dander, latex, mixed flours, wheat and bran flour
(Omega, Montreal, Canada) that were used in previous studies, were completed in the same subjects. A wheal diameter of $3 \mathrm{~mm}$ or more was regarded as a positive response, after subtraction of any response to the negative control (glycerine $50 \%$ ). Sensitisation to laboratory animal allergens was defined as a positive SPT response to any occupational allergen. Atopy was defined as a positive skin-test reaction to at least two of 11 common inhalants. ${ }^{13}$

Bronchial methacholine challenge tests were performed using guidelines slightly modified from those of the European Respiratory Society. ${ }^{15}$ The procedure for performing the methacholine test was modified as described elsewhere to take into account the absence of an onsite physician. ${ }^{16}$

\section{Outcomes}

We used new cases of occupational sensitisation, BHR, rhinoconjunctival, and chest symptoms at work as outcomes. Occupational sensitisation was defined as a new positive reaction to at least one relevant occupational HMW allergen at follow-up. Incident cases of BHR were defined as a significant increase in bronchial responsiveness at follow-up compared with BHR measured at entry into the training programme (3.2fold or greater decrease in methacholine provocation concentration which causes a $20 \%$ fall in forced expiratory volume in 1 second $\left(\mathrm{FEV}_{1} ; \mathrm{PC}_{20} \mathrm{FEV}_{1}\right),{ }^{17}$ or a change at follow-up to a $\mathrm{PC}_{20}$ $\leqslant 16 \mathrm{mg} / \mathrm{ml}$ in subjects with an initial $\mathrm{PC}_{20}>32 \mathrm{mg} / \mathrm{ml}$ ). Rhinoconjunctival symptoms at work were considered present if a worker experienced at least one eye or nasal problem during work; chest symptoms at work were defined when experiencing cough, wheeze, shortness of breath, and/or chest tightness during work; incident cases were workers who had symptoms at work after their apprenticeship.

\section{Different measures of continued exposure to relevant HMW allergens after training \\ Self-reported and investigator scoring on job-training relatedness}

A detailed work history was obtained on job(s) held since ending an apprenticeship, with start and end dates, number of hours/week, type of industry, and main activity in the workplace. In order to assess continuation of exposure to relevant HMW allergens during follow-up, participants were asked to report if their jobs were related to their training.

A three-point investigator score was also assigned: score $0=$ not related; $1=$ main activity workplace related; and
Figure 1 Study participation of animal health technology, pastry making, and dental hygiene technology apprentices with an 8-year follow-up after training. Participants were considered eligible if they did not have an outcome at the end of apprenticeship. Of those who were eligible, participants without skin prick test results to common allergens at the end of apprenticeship were excluded from the analysis. BHR, bronchial hyperresponsiveness; PY, person-year.
Outcome

.

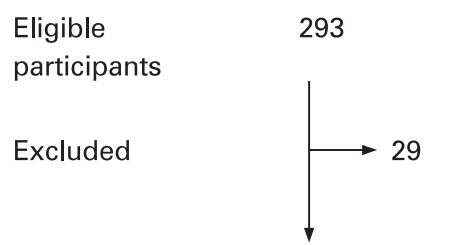

Analysed

(per 100 PY)

$21(1.1)$
Incident cases
Rhino-

conjunctival symptoms

250

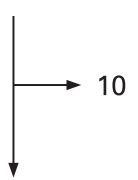

240

$26(1.5)$
Chest symptoms

366

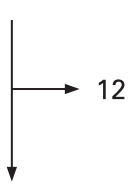

350

$19(0.5)$

\section{Occupational} sensitisation

264
BHR
535
771
238

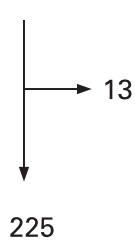

32 (2.0)
Number of jobs 
$2=$ activities and job title related to training programme. This score was assigned by two investigators blinded to allergic status at follow-up. For instance, a score of 0 was assigned for a hair stylist who had training in pastry making; a score of 1 was assigned to a secretary in a veterinary clinic who had training in animal health technology; and a score of 2 was assigned for a baker or confectioner who had training in pastry making. A job was considered related to training if score $\geqslant 1$. A participant was considered as having a job related to training if they worked for the equivalent of 1 year or more for at least $40 \mathrm{~h} /$ week in the job. Duration of work was computed and summed for all jobs considered related to training (variable: working years). The sum product of multiplication between duration of work and weekly working hours in the related jobs was also calculated.

\section{The asthma-specific JEM}

Jobs were coded using the International Standard Classification of Occupations (ISCO)-88 system ${ }^{18}$ (performed by ES and DG). Subsequently ISCO codes were linked to the asthma-specific JEM developed by Kennedy et al, ${ }^{6}$ and the subsequent verification step recommended as part of the JEM method was also included. The JEM classified exposure (yes or no) to 18 asthmagenic compounds, classes of compounds, or mixed environments for every job title listed in ISCO-88. Based on the presence and absence of the 18 exposure classifications, a high-asthma risk group is identified, which includes jobs with exposure to HMW allergens, low molecular weight (LMW) allergens, mixed environment allergens and jobs with a high probability of accidental peak exposure to irritants. The JEM also identifies a low-asthma risk group, which includes jobs with exposure to combustion particles, tobacco, and other possible irritants, gas, or fumes, and jobs unlikely to represent an asthma risk. Exposures were coded " 1 " only for jobs with a strong likelihood of exposure relevant to work-related asthma, that is, a high probability of most workers in that job being exposed to agents that would put them at high risk of developing occupational asthma. This step was followed by verification on ISCO coding and exposure assignments as recommended by the JEM. ${ }^{6}$ Verification was carried out by one author who was knowledgeable of the possible exposure at workplace (DG), blinded to outcome status at follow-up. For example, life science technicians who worked with laboratory animals were assigned to have exposure to HMW animalderived allergens. In addition to the verification guidelines provided by the JEM, DG assigned positive exposure to latex allergens for life science technicians who worked with laboratory animals. She also assigned exposure to latex and animal-derived allergens for college, university and highereducation teaching professionals in animal health technology. The decision to classify these jobs as exposed to latex was determined following a telephone consultation with several participants who work as dentist assistants, veterinary assistants, veterinarians, life science technicians, and lecturers in animal health technology, who confirmed the use of latex gloves.

\section{Data analysis}

After completion of job coding and exposure classification, a Cox proportional hazards analysis ${ }^{19}$ was conducted to evaluate the association between outcome and exposure surrogates which were the assessments of continued exposure to relevant HMW allergens after training (self-reported, investigator scoring, and exposure categories generated by the JEM). Hazard ratios and their corresponding 95\% CIs were estimated. Atopic status at the end of training and smoking habit (ever smoked) from entry in training until follow-up were included in the analysis as fixed covariates. ${ }^{1}$ Age and gender were not included except in the analysis of incidence of BHR. ${ }^{20}$ The association between the outcomes and exposure duration variables (total working years as well as the product of the sum of multiplication between working years and weekly working hours in the related job) were similarly evaluated.

At first, all exposure categories derived from the JEM were analysed separately. Due to limited sample size, the reference group was comprised of participants who were not exposed to a particular asthmagenic compound (e.g., to estimate hazard ratio of exposure to animal-derived allergens, the reference group was participants who were not exposed to animal-derived allergens). Hazard ratios were estimated for exposure categorisation. Next, exposure categories were dichotomised into exposed or not exposed to HMW allergen. Kappa statistics was performed to measure the agreement between self-reported, investigator scoring, and the dichotomised JEM exposure categories. All statistical analyses were performed with SPSS software (version 14).

\section{RESULTS}

Of the 375 participants, the mean age was 23.9 (standard deviation, SD 5.5) years; $13.6 \%$ were male; $27 \%$ had ever smoked; and $42 \%$ had positive SPT to at least two of 11 common antigens at the end of their training. Fifty-seven participants were trained in dental hygiene technology, 73 in pastry making, and 245 in animal health technology. Twentyone participants developed new sensitisation to occupational allergens during follow-up (mean (SD) duration of follow-up was 7.3 (1.8) years) (fig 1). A new case of probable occupational asthma - defined as a positive occupational sensitisation and methacholine bronchial challenge - was found in only seven participants.

\section{Exposure}

Based on the first JEM verification step (coding verification), there were six job titles that needed ISCO-coding verification: armed forces; hand packers and other manufacturing labourers; market gardeners and crop growers; teaching professionals, not elsewhere classified; production and operations department managers; and textile, garment and related trade workers. No correction was made because there was no other job code that could best describe the work performed. In the exposure verification, 366 job titles from 227 participants needed exposure verification. Corrections were made for 121 job titles from 77 participants. Most of the changes were the removal of exposure to enzyme in 93 pastry makers, but their exposure to flour was retained. Aside from verification required by the JEM, an additional 135 exposure corrections were made for 101 participants. Exposure to HMW latex allergens was assigned to life science technicians who worked with laboratory animals (96 corrections). College, university, or higher-education professionals who had contact with animals in their teaching activity were assigned to have positive exposure to HMW animalderived and latex allergens (each 16 corrections).

The five most frequently occurring jobs held during the follow-up period, which comprised $63.5 \%$ of the total jobs held by the participants, were veterinary assistants, veterinarians, dentist assistants, bakers and/or pastry makers, and life science technicians (table 1). Sixty-eight jobs were in the LMW agentsexposed group, of which $44(64.7 \%)$ were dental assistants who 
Table 1 Distribution of exposure to high (HMW) and low molecular weight (LMW) allergens according to job code in the five most frequent jobs during follow-up

\begin{tabular}{llllll}
\hline & $\begin{array}{l}\text { Bakers and/or } \\
\text { pastry makers }\end{array}$ & $\begin{array}{l}\text { Dental } \\
\text { assistants }\end{array}$ & $\begin{array}{l}\text { Life science } \\
\text { technicians }\end{array}$ & Veterinarians & $\begin{array}{l}\text { Veterinary } \\
\text { assistants }\end{array}$ \\
\hline No & 23 & 44 & 47 & 60 & 64 \\
HMW allergens & $*$ & $*$ & $*$ & $*$ \\
$\quad$ Animal derived & $*$ & & $*$ & $*$ \\
$\quad$ Flour & $*$ & $*$ & $*$ & $*$ \\
$\quad$ Enzymes & & & & \\
$\quad$ Latex & $*$ & & \\
LMW agents & $*$ & & \\
$\quad$ Highly reactive chemicals & $*$ & & \\
Metal sensitisers, fumes & & $*$ & &
\end{tabular}

were exposed to both HMW (i.e., latex) and LMW (i.e., highly reactive chemical and metal or metal fumes) agents.

Relations between occupational exposures generated by the asthma-specific JEM, before and after exposure verification, and incidence of occupational sensitisation during follow-up are presented in table 2. Exposure to HMW animal-derived allergens in the workplace (e.g., veterinarian and veterinarian assistant) significantly increased the risk of developing sensitisation by three and six times (before and after verification, respectively) compared with those who were not exposed (table 2).

For rhinoconjunctival and chest symptoms at work and BHR, the risk associated with exposure was also estimated for exposure categories other than HMW allergens (tables 3 and 4). Overall, verification of the presence of exposure at the workplace, by incorporating information on job task and main activity of the workplace, assigned more workers to the exposed group and consistently increased the risk of developing the outcomes. For example, the risks of developing rhinoconjunctival symptoms at work among workers exposed to animalderived allergens before and after verification were 2.2 (95\% CI 1.0 to 4.9$)$ and 2.6 (95\% CI 1.1 to 6.2$)$, respectively.

Exposure to metal working fluids significantly increased the risk of developing chest symptoms, but the CI was very wide because one of the two exposed participants developed the outcome. Exposure to highly reactive chemical or metal sensitisers increased the risk of having a significant increase in bronchial responsiveness by two to three times compared with those who were not exposed.

All methods assessing continued exposure to relevant HMW allergens during follow-up: self-reported, investigator scoring, and the JEM revealed that most (more than 90\%) of the participants from animal health and dental hygiene technology apprenticeship at least had one job with exposure to relevant HMW allergens once they entered the workforce. Lower percentages were found among participants who trained in pastry making $(72-76 \%)$. From the questionnaires, 629 of 834 (75.4\%) jobs were reported as related to training by $320(85.6 \%)$ participants. Exposure assignment generated by the JEM resulted in 637 (76.4\%) jobs with the presence of HMW allergen exposure at the workplace.

The agreement between self-reported and investigator scoring on the job-training relatedness was very good (kappa, $k=0.92$ ). The kappa values between self-reported and HMW allergens exposure category generated by the JEM were 0.56 (before exposure verification) and 0.80 (after exposure verification). The agreements between investigator scoring and HMW allergens exposure category generated by the JEM were $k=0.52$ and $k=0.79$ for before and after exposure verification, respectively.

We found consistent associations between the outcomes and each exposure proxy variable as could be expected given the high association reflected by kappa values (table 5). For chest symptoms at work, investigator scoring and the JEM before verification showed a reduced risk whereas the other two methods showed an increased risk. This variation could be expected given the wide CIs with the lowest interval below the value " 1 " and the highest over " 1 ".

\section{Duration of exposure}

After adjustment for atopic status and smoking habit, there was no significant association between the outcomes and working years or the product of a multiplication between years of work and weekly working hours in the related job. Nevertheless, it

Table 2 Relation between occupational exposures generated by the asthma-specific job exposure matrices and sensitisation to occupational high molecular weight (HMW) allergens during follow-up (adjusted for atopy and smoking habits)

\begin{tabular}{|c|c|c|c|c|}
\hline \multirow[b]{2}{*}{ Exposure category } & \multicolumn{2}{|c|}{ Before verification } & \multicolumn{2}{|c|}{ After verification } \\
\hline & $\mathrm{i} / \mathbf{n}$ & HR $(95 \%$ CI) & $\mathrm{i} / \mathbf{n}$ & HR (95\% CI) \\
\hline HMW allergens & $17 / 211$ & $1.2(0.4$ to 3.7$)$ & $20 / 229$ & $4.6(0.6$ to 34.2$)$ \\
\hline Animal derived & $11 / 120$ & $3.0(1.2$ to 7.4$)$ & $15 / 138$ & $6.4(2.3$ to 18.2$)$ \\
\hline Fish & - & & $0 / 1$ & \\
\hline Flour & $3 / 40$ & $0.4(0.1$ to 1.2$)$ & $3 / 41$ & $0.4(0.1$ to 1.2$)$ \\
\hline Plant & - & & $0 / 1$ & \\
\hline Arthropods, mites & - & & - & \\
\hline Enzymes & $3 / 40$ & $0.4(0.1$ to 1.2$)$ & $1 / 3$ & $1.4(0.2$ to 11.8$)$ \\
\hline Latex & $14 / 172$ & $2.5(0.9$ to 6.8$)$ & $17 / 190$ & 5.5 (1.5 to 19.5$)$ \\
\hline Bio-aerosols & $0 / 3$ & & $0 / 3$ & \\
\hline Pharmaceutical product & $0 / 4$ & & $0 / 4$ & \\
\hline
\end{tabular}

$\mathrm{HR}$, hazards ratio; $\mathrm{i} / \mathrm{n}$, incident cases/number of participants in the exposure category. 
Table 3 Relation between occupational exposures generated by the asthma-specific job exposure matrices (before verification) and various outcomes during follow-up

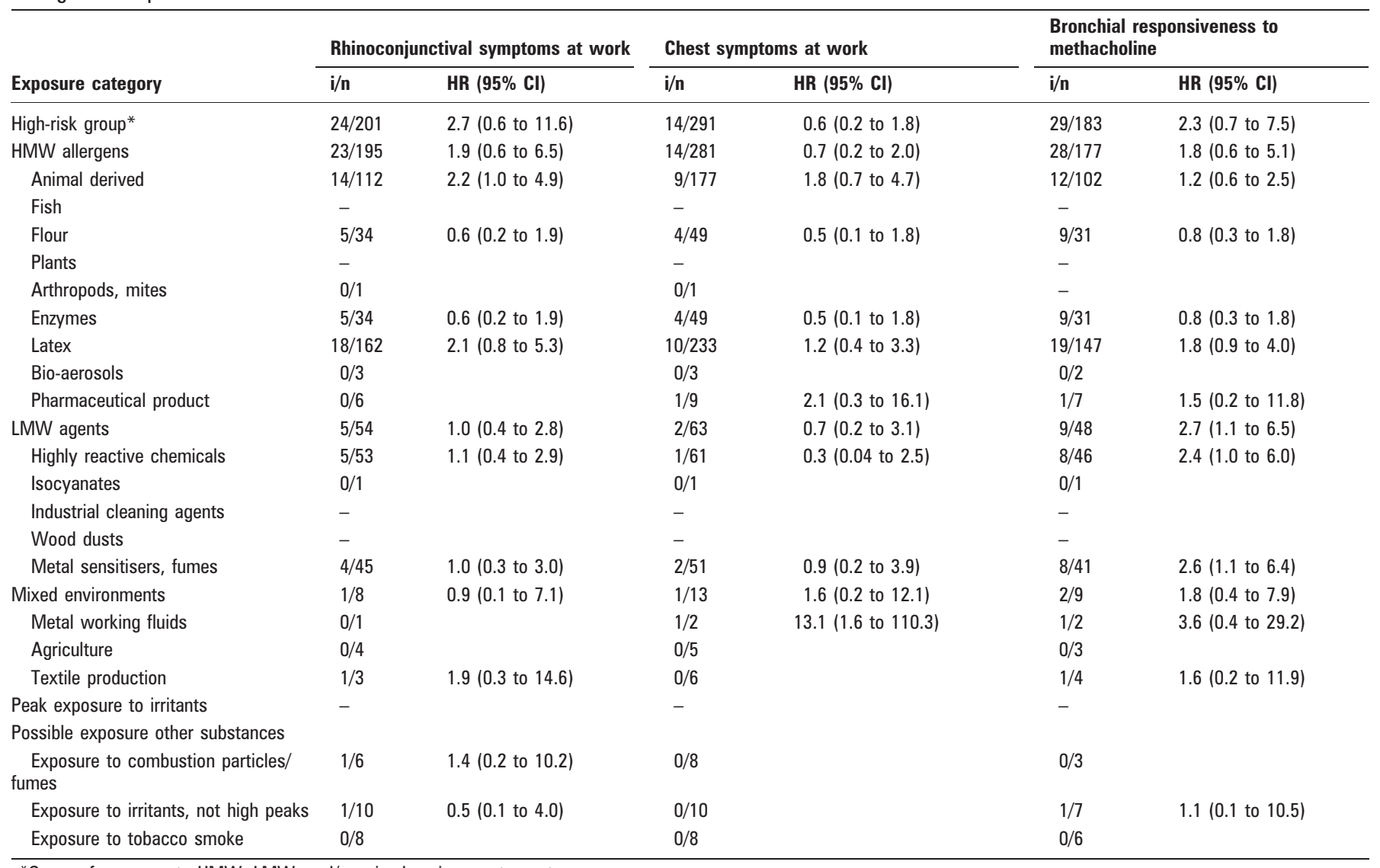

${ }^{*}$ Group of exposure to HMW, LMW, and/or mixed-environment agents.

HMW, high molecular weight; HR, hazards ratio; i/n, incident cases/number of participants in the exposure category; LMW, low molecular weight.

was noteworthy that atopic participants developed occupational sensitisation and symptoms at work in a shorter period than the non-atopic participants (data not shown).

\section{DISCUSSION}

Our study demonstrated that the risk of occupational allergies associated with the presence or absence of exposure at the workplace can be estimated by the asthma-specific JEM. Consistent with self-reported and investigator scoring on jobtraining relatedness, the matrix showed that being further exposed to HMW allergens played an important role in the development of new cases of occupational sensitisation, rhinoconjunctival symptoms at work, and BHR. ${ }^{21}{ }^{22}$ Exposure verification appeared to be important to optimise the sensitivity and the specificity, as well as hazard ratios produced by the JEM.

It is interesting that the JEM, which was specifically developed to estimate the attributable risk for occupational asthma (or work-related asthma) in general populations, ${ }^{6}$ seems to provide a good estimation of the risk of the development of occupational sensitisation, BHR, and rhinoconjunctival symptoms at work in a more or less homogeneous population in the sense that more than $75 \%$ of the participants had jobs with exposure to asthmagenic compounds in the workplace. These findings suggest that using the asthma-specific JEM to estimate the risk of outcomes of occupational allergies associated with related underlying mechanisms is effective. ${ }^{23} 24$ Both workrelated asthma and rhinitis can occur, but not exclusively, through sensitisation to specific agents at the workplace.
Sensitisation to HMW agents is mediated by immunoglobulin E (IgE), while sensitisation to LMW agents involves both IgE and other less well understood mechanisms.

The exposure verification step integrated in the JEM seemed to optimise the JEM sensitivity and specificity. Except for exposure to enzyme, the verification step assigned more relevant exposures to the associated job titles and thus, yielded a substantial improvement of the exposure risk estimation: risk of developing the outcomes overall was doubled after the exposure verification step. For exposure to enzyme, this step seemed to increase the specificity of the JEM. A study by Tielemans and colleagues demonstrated that specificity drives the effect of misclassification on measures of association in studies with a low prevalence of exposure. ${ }^{25}$ McGuire and colleagues in their review concluded that when more information from the job task and industry information is added to a JEM, the specificity in the assignment of exposure increased, and the likelihood that an association between exposure and diseases will be detected also increases. ${ }^{7}$ Nevertheless, the population under study was previously exposed to HMW allergens during their apprenticeship and a high proportion of them work in industries with a high risk for work-related allergies. Given a high prevalence of exposure, an exposure assessing method with high sensitivity is necessary to obtain a less biased association.

It is acknowledged that exposure to occupational sensitisers, both HMW and LMW agents, can increase BHR ( $\mathrm{FEV}_{1}$ decreases after inhalation to methacholine or histamine). ${ }^{26}{ }^{27}$ Interestingly, we found that exposure to LMW agents significantly increased 
Table 4 Relation between occupational exposures generated by the asthma-specific job exposure matrices (after verification) and various outcomes during follow-up

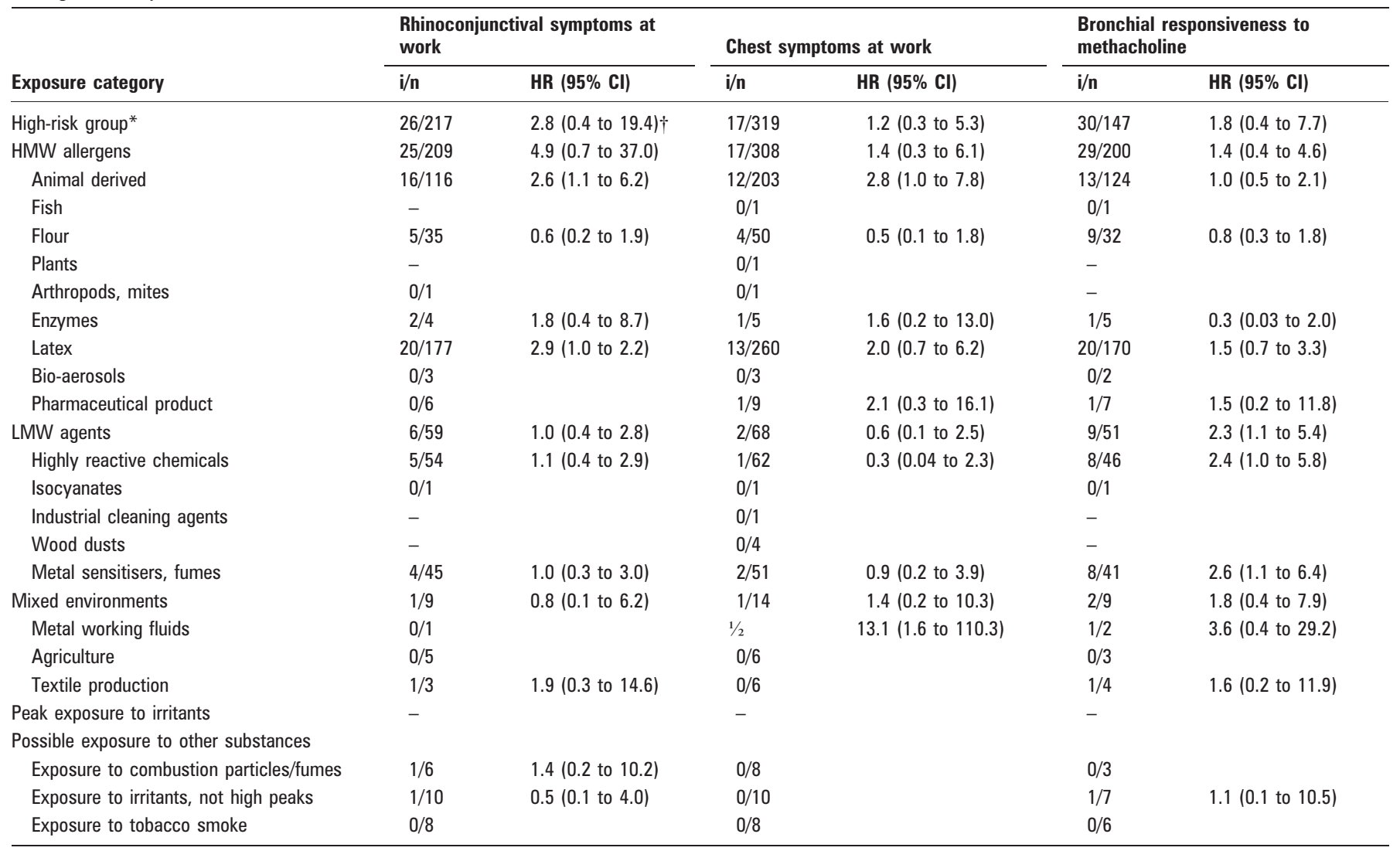

*Group of exposure to HMW, LMW, and/or mixed-environment agents.

$\dagger$ There was no case in the unexposed group. Therefore, the crude relative risk was calculated as if there was one case in the unexposed group.

HMW, high molecular weight; HR, hazards ratio; i/n, incident cases/number of participants in the exposure category; LMW, low molecular weight.

the risk of developing BHR in a higher magnitude than exposure to HMW allergens (relative risk 2.3 (95\% CI 1.1 to 5.4 ) vs 1.4 (95\% CI 0.4 to 4.6) for LMW and HMW category, respectively). However, the fact that all participants were previously exposed to HMW allergens during training should be taken into account in interpreting the risk estimates. Moreover, $90 \%$ of the participants in the LMW agents-exposed group were employed as dentist assistants who were simultaneously exposed to latex allergen, highly reactive chemical and metal fume antigens. Therefore, the high risk of BHR in this group might be explained by concomitant exposure to HMW and LMW allergens. This finding illustrates the limitation of JEM that treats each exposure category as if they were independent, whereas multiple exposures at the workplace are common in real-life situations. Zock and colleagues recommended that multiple-exposure patterns instead of single-exposure categories when calculating risks of workrelated asthma be taken into account. ${ }^{9}$

Another interesting point was that all assessment methods of continued exposure to relevant HMW allergens after training self-reported, investigator scoring, and the exposures categories derived from the JEM - showed moderate to good agreement. All of them were associated with increased risks of developing the outcomes, although none of the associations were statistically significant, which might be explained by limited sample size. For application in practice, the JEM is a simple method in assessing exposure in the workplace. Nevertheless, it is relatively labour intensive given the fact that the exposure verification step by experts appeared to be very important to increase sensitivity and relative risks. Self-reported continued exposure to HMW allergens was simpler and even though not exposure

Table 5 Relation between the incidence of various outcomes and different measures of continued exposure to relevant high molecular weight allergens after training

\begin{tabular}{|c|c|c|c|c|c|c|c|c|}
\hline & \multicolumn{2}{|c|}{$\begin{array}{l}\text { Occupational sensitisation } \\
\text { (n=21) }\end{array}$} & \multicolumn{2}{|c|}{$\begin{array}{l}\text { Rhino-conjunctivitis at work } \\
(\mathrm{n}=26)\end{array}$} & \multicolumn{2}{|c|}{$\begin{array}{l}\text { Chest symptoms at work } \\
(\mathrm{n}=19)\end{array}$} & \multicolumn{2}{|c|}{$\operatorname{BHR}(n=32)$} \\
\hline & $i / n$ & HR (95\% CI) & $i / n$ & HR $(95 \%$ CI) & $i / n$ & HR (95\% CI) & $i / n$ & HR $(95 \%$ CI) \\
\hline Self-reported & $21 / 233$ & $2.8(0.4 \text { to } 20.1)^{*}$ & $26 / 210$ & $3.7(0.5 \text { to } 26.4)^{*}$ & $17 / 310$ & $1.2(0.3$ to 5.3$)$ & 29/198 & $1.7(0.5$ to 5.6$)$ \\
\hline Investigator scoring & $21 / 230$ & $3.1(0.4 \text { to } 22.3)^{*}$ & $23 / 207$ & $1.7(0.5$ to 5.8$)$ & $16 / 305$ & $0.9(0.3$ to 3.1$)$ & 29/195 & $1.8(0.6$ to 6.1$)$ \\
\hline $\begin{array}{l}\text { Asthma-specific JEM } \\
\text { (before verification) }\end{array}$ & $17 / 211$ & $1.2(0.4$ to 3.7$)$ & $23 / 195$ & $1.9(0.6$ to 6.5$)$ & $14 / 281$ & $0.7(0.2$ to 2.0$)$ & $28 / 177$ & $1.8(0.6$ to 5.1$)$ \\
\hline $\begin{array}{l}\text { Asthma-specific JEM (after } \\
\text { verification) }\end{array}$ & $20 / 229$ & 4.6 (0.6 to 34.2 ) & $25 / 209$ & $4.9(0.7$ to 37.0$)$ & $17 / 308$ & $1.4(0.3$ to 6.1$)$ & $29 / 200$ & $1.4(0.4$ to 4.6$)$ \\
\hline
\end{tabular}

* There was no case in the unexposed group. Therefore, the crude relative risk was calculated as if there was one case in the unexposed group.

BHR, bronchial hyper-responsiveness; HR, hazards ratio; i/n, incident cases/number of participants in the exposure category; JEM, job exposure matrix. 
Main messages

- The asthma-specific job exposure matrix (JEM) could be utilised to estimate the risk of a broad outcome related to occupational allergies with a similar underlying mechanism. Exposure verification appeared to be important to optimise the sensitivity and the specificity, as well as hazard ratios produced by the JEM.

- All assessment methods of continued exposure to relevant high molecular weight allergens after training — self-reported, investigator scoring, and the exposures categories derived from the JEM - showed moderate to good agreement. All of them were associated with increased risks of developing occupational sensitisation, rhinoconjunctival symptoms at work, and bronchial hyper-responsiveness.

specific, it produced crude estimations on how likely apprentices in animal health technology, pastry making, or dental hygiene will develop occupational allergies after they enter the workforce with exposure to relevant allergens. Previous studies demonstrated that self-reported occupational exposures were related to symptoms of asthma and bronchitis, ${ }^{82}$ but less clearly to the objective outcomes of pulmonary function and BHR. ${ }^{28}$ It seems that this was not an issue in this study since the participants were not asked about the possible exposures in their workplace (self-reported exposure); the continued exposure to HMW allergens was inferred from questions on whether their jobs were related to their training.

A good awareness of job-training relatedness is expected to facilitate avoidance for future exposure among those who early developed occupational sensitisation or allergic symptoms during training. Nevertheless, it appears that continued exposure to occupational allergens is inevitable among apprentices in health and dental hygiene technology. Based on selfreports (as well as two other methods), more than $90 \%$ of participants from these apprenticeships had a job(s) with continued exposure to relevant allergens at the workplace. Therefore, awareness of the possible development of occupational allergic diseases should be fostered and preventive measures should be implemented; for example, substitution of latex gloves with non-latex gloves and the use of protective equipments to reduce exposure. ${ }^{29}$

Previously, Nieuwenhuijsen and colleagues demonstrated that duration of exposure was not an important factor for the incidence of occupational allergies. ${ }^{3}$ Current authors also found that work duration in job(s) related to training programme (i.e., job with relevant exposure to HMW allergens) was not associated with the incidence of outcomes. The reasons for not appearing as a predictor may, however, differ from the Nieuwenhuijsen study. In the current study, duration differs very little between individuals because the study population is very young with a low maximal number of exposure-years. Hence, the probability to have a significant association between work duration and incidence of the outcomes is very low. Nevertheless, the average of work duration among atopic participants who developed outcomes was shorter than their non-atopic colleagues. This is consistent with results from a pooled study in laboratory animal workers that atopics are at a higher risk of developing chest symptoms and sensitisation. ${ }^{20}$

In conclusion, this analysis indicates that it is possible to utilise the asthma-specific JEM to estimate exposure risk for

\section{Policy implications}

- Since continued exposure to relevant allergens beyond training is very likely, primary prevention should be implemented in the workplace; for example, the substitution of natural rubber latex gloves and the use of protective equipment.

- The asthma-specific job exposure matrices could be used to estimate the risk of various outcomes of occupational allergies associated with exposure to high molecular weight and low molecular weight allergens, but it is relatively labour intensive since an additional exposure verification step appeared to be very important to optimise its sensitivity and specificity.

broad outcomes related to occupational allergies. Continued exposure to relevant HMW allergens significantly increased the risk of developing occupational sensitisation and rhinoconjunctival symptoms at work. Our finding suggested that concomitant exposure to HMW and LMW agents significantly increased the risk of developing BHR. Exposure verification is an important integrated step in the JEM that optimised the performance of the matrix. The JEM performance was in agreement with self-reported and investigator scoring on the prolongation of exposure to relevant allergens after training in apprentices in animal health technology, pastry making, or dental hygiene.

Acknowledgements: This study was supported by the Canadian Institutes of Health Research (Grant MOP-53118), the Medical Research Council of Canada (Grant MT12256), and the Institut de recherche Robert-Sauvé en santé et en sécurité du travail (Grant 099-164). One author (ES) is a research fellow with a grant from the Center for Asthma in the Workplace-Canadian Institutes of Health Research.

Competing interests: None.

\section{REFERENCES}

1. Nicholson PJ, Cullinan P, Taylor AJ, et al. Evidence based guidelines for the prevention, identification, and management of occupational asthma. Occup Environ Med 2005;62:290-9.

2. Heederik D, Venables KM, Malmberg P, et al. Exposure-response relationships for work-related sensitization in workers exposed to rat urinary allergens: results from a pooled study. J Allergy Clin Immunol 1999;103:678-84.

3. Nieuwenhuijsen MJ, Putcha V, Gordon S, et al. Exposure-response relations among laboratory animal workers exposed to rats. Occup Environ Med 2003;60:104-8.

4. Tielemans $\mathbf{E}$, Heederik D, Burdorf A, et al. Assessment of occupational exposures in a general population: comparison of different methods. Occup Environ Med 1999;56:145-51.

5. Benke G, Sim M, Fritschi L, et al. Comparison of occupational exposure using three different methods: hygiene panel, job exposure matrix (JEM), and self reports. App/ Occup Environ Hyg 2001;16:84-91.

6. Kennedy SM, Le Moual N, Choudat D, et al. Development of an asthma specific job exposure matrix and its application in the epidemiological study of genetics and environment in asthma (EGEA). Occup Environ Med 2000;57:635-41.

7. McGuire V, Nelson LM, Koepsell TD, et al. Assessment of occupational exposures in community-based case-control studies. Annu Rev Public Health 1998;19:35-53.

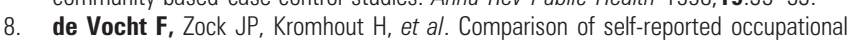
exposure with a job exposure matrix in an international community-based study on asthma. Am J Ind Med 2005;47:434-42.

9. Zock JP, Cavalle N, Kromhout H, et al. Evaluation of specific occupational asthma risks in a community-based study with special reference to single and multiple exposures. J Expo Anal Environ Epidemiol 2004;14:397-403.

10. Radon K, Gerhardinger U, Schulze A, et al. Occupation and adult onset of rhinitis in the general population. Occup Environ Med 2008;65:38-43.

11. Gautrin D, Ghezzo H, Infante-Rivard C, et al. Incidence and determinants of lgEmediated sensitization in apprentices. A prospective study. Am J Respir Crit Care Med 2000;162:1222-8.

12. Gautrin D, Ghezzo H, Infante-Rivard C, et al. Long-term outcomes in a prospective cohort of apprentices exposed to high-molecular-weight agents. Am J Respir Crit Care Med 2008;177:871-9.

13. Gautrin D, Infante-Rivard C, Dao T, et al. Specific IgE-dependent sensitization, atopy, and bronchial hyperresponsiveness in apprentices starting exposure to proteinderived agents. Am J Respir Crit Care Med 1997;155:1841-7. 
14. Burney PG, Laitinen LA, Perdrizet $S$, et al. Validity and repeatability of the IUATLD (1984) Bronchial Symptoms Questionnaire: an international comparison. Eur Respir J 1989;2:940-5.

15. Sterk PJ, Fabbri LM, Quanjer PH, et al. Airway responsiveness. Standardized challenge testing with pharmacological, physical and sensitizing stimuli in adults. Report Working Party Standardization of Lung Function Tests, European Community for Steel and Coal. Official Statement of the European Respiratory Society. Eur Respir J Supp/ 1993;16:53-83.

16. Troyanov S, Malo JL, Cartier A, et al. Frequency and determinants of exaggerated bronchoconstriction during shortened methacholine challenge tests in epidemiological and clinical set-ups. Eur Respir J 2000;16:9-14.

17. Dehaut $\mathbf{P}$, Rachiele A, Martin RR, et al. Histamine dose-response curves in asthma: reproducibility and sensitivity of different indices to assess response. Thorax 1983;38:516-22

18. ILO. International Standard Classification of Occupations: ISCO 88. Geneva: ILO, 1991.

19. Cox D. Regression models and life tables. JR Stat Soc B 1972;34:187-220.

20. Kruize H, Post W, Heederik D, et al. Respiratory allergy in laboratory animal workers: a retrospective cohort study using pre-employment screening data. Occup Environ Med 1997; 54:830-5.

21. Malo JL, Lemiere C, Gautrin D, et al. Occupational asthma. Curr Opin Pulm Med 2004;10:57-61.
22. Hytonen M, Kanerva L, Malmberg $\mathrm{H}$, et al. The risk of occupational rhinitis. Int Arch Occup Environ Health 1997;69:487-90.

23. Gautrin D, Desrosiers M, Castano R. Occupational rhinitis. Curr Opin Allergy Clin Immunol 2006:6:77-84.

24. Maestrelli P, Fabbri LM, Mapp CE. Pathophysiology. In: Bernstein I, Chan-Yeung M, Malo J-L, Bernstein D, eds. Asthma in the workplace. 3rd edn. New York: Taylor \& Francis, 2006: 109-140.

25. Tielemans E, Burdorf A, te Velde ER, et al. Occupationally related exposures and reduced semen quality: a case-control study. Fertil Steril 1999;71:690-6.

26. Cartier A, L'Archeveque J, Malo JL. Exposure to a sensitizing occupational agent can cause a long-lasting increase in bronchial responsiveness to histamine in the absence of significant changes in airway caliber. J Allergy Clin Immunol 1986;78:1185-9

27. Malo JL, Cartier A, Lemiere C, et al. Exaggerated bronchoconstriction due to inhalation challenges with occupational agents. Eur Respir J 2004:23:300-3.

28. Kogevinas M, Anto JM, Sunyer J, et al. Occupational asthma in Europe and other industrialised areas: a population-based study. European Community Respiratory Health Survey Study Group. Lancet 1999;353:1750-4.

29. Tarlo SM, Liss GM. Prevention of occupational asthma--practical implications for occupational physicians. Occup Med (Lond) 2005:55:588-94. 